\title{
A Robust Potato Model: LINTUL-POTATO-DSS
}

\author{
A. J. Haverkort ${ }^{1,2}$ - A. C. Franke ${ }^{3}$. J. M. Steyn ${ }^{2}$. \\ A. A. Pronk ${ }^{1}$ • D. O. Caldiz ${ }^{4}$ P. L. Kooman ${ }^{5}$
}

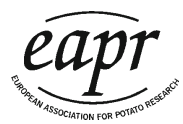

Received: 29 April 2015 / Accepted: 30 September 2015 /

Published online: 31 October 2015

(C) The Author(s) 2015. This article is published with open access at Springerlink.com

\begin{abstract}
In 1994, LINTUL-POTATO was published, a comprehensive model of potato development and growth. The mechanistic model simulated early crop processes (emergence and leaf expansion) and light interception until extinction, through leaf layers. Photosynthesis and respiration in a previous crop growth model-SUCROSwere substituted by a temperature-dependent light use efficiency. Leaf senescence at initial crop stages was simulated by allowing a longevity per daily leaf class formed, and crop senescence started when all daily dry matter production was allocated to the tubers, leaving none for the foliage. The model performed well in, e.g., ideotyping studies. For other studies such as benchmarking production environments, agroecological zoning, climatic hazards, climate change, and yield gap analysis, the need was felt to develop from the original LINTUL-POTATO, a derivative LINTULPOTATO-DSS with fewer equations - reducing the potential sources of error in calculations - and fewer parameters. This reduces the number of input parameters as well as the amount of data required that for many reasons are not available or not reliable. In LINTUL-POTATO-DSS calculating potential yields, initial crop development depends on a fixed temperature sum for ground cover development from $0 \%$ at emergence to $100 \%$. Light use efficiency is temperature dependent. Dry matter distribution to the
\end{abstract}

\section{A. A. Pronk \\ annette.pronk@wur.nl}

1 Wageningen University and Research Centre, Plant Research International, P.O. Box 616, 6700 AP Wageningen, The Netherlands

2 Department of Plant Production and Soil Science, University of Pretoria, Pretoria 0002, South Africa

3 Department of Soil, Crop and Climate Sciences, University of the Free State, Bloemfontein 9300, South Africa

4 Global Agronomy R\&D, McCain Foods Limited, Ruta 226 Km 61, 500 B7620EMA Balcarce, Argentina

5 CAH Vilentum, De Drieslag 4, 8251 JZ Dronten, The Netherlands 
tubers starts at tuber initiation and linearly increases up to a fixed harvest index which is reached at crop end. Crop end is input of the model: it is assumed that the crop cycle determined by maturity matches the length of the available frost-free and or heat-free cropping season. LINTUL-POTATO-DSS includes novel calculations to explore tuber quality characteristics such as tuber size distribution and dry matter concentration depending on crop environment and management.

Keywords Climate change - Crop growth modeling - Irrigation - Light use efficiency · Nitrogen · Potassium · Tuber dry matter - Tuber size distribution

\section{Introduction}

\section{LINTUL-POTATO-1.0}

Although Alberda (1962) considered potato when comparing actual and potential yields of crops and De Wit (1964) also modeled photosynthesis of potato, the first comprehensive potato crop model was published by $\mathrm{Ng}$ and Loomis (1984). It made use of the SUCROS model (Van Keulen et al. 1982) that calculates potential growth from light extinction in the canopy, photosynthesis, respiration, and dry matter allocation. Later, the WOFOST model (Van Diepen et al. 1989) took soil and water relations into account, allowing a more accurate simulation of actual yields. SUBSTOR (Ritchie et al. 1995) was developed for ideotyping, agrozoning, and decision support as part of some 30 different crop models. The original LINTUL-POTATO model was developed in the early 1990s by Kooman and Haverkort (1994). The objectives of this paper are to describe the change of the LINTUL potato model from a scientific tool to a tool that is used by the potato industry for yield and quality forecasting, for yield gap analysis, and assessing weather and climate hazards.

LINTUL-POTATO was based on models describing dry matter accumulation as a function of light (solar radiation) interception and light use efficiency by Spitters (1990) and Spitters and Schapendonk (1990). Dry matter allocation to the various plant organs is modeled by assuming a temperature-dependent crop development. LINTULPOTATO aimed to explain dry matter production and distribution of potato crops under field conditions varying in photoperiod and temperature for use in ideotyping and agrozoning (Haverkort and Kooman 1997).

In LINTUL-POTATO, crop development starts at planting. The seed tuber is planted at an indicated depth and the moment of emergence depends on the temperaturedependent sprout growth rate with a maximum value of $1 \mathrm{~mm}\left({ }^{\circ} \mathrm{Cd}\right)^{-1}$. Also, light use efficiency is temperature dependent. The base temperature for crop development is $2.2{ }^{\circ} \mathrm{C}$. The model assumes that the early phases of crop development are temperature driven as they only involve metabolic processes (mobilizing carbon from the mother tuber to the emerging sprout) and to leaf expansion well before canopy closure. It is assumed that the role of the mother tuber as deliverer of energy stops when the leaf area index (LAI) exceeds 0.75 . To simulate crop senescence, the leaves are divided into cohorts according to the day in which they were formed and die or become ineffective when exceeding a cumulative temperature sum defined as their longevity, when they have more than a threshold number of leaves above them, or when daily growth is all 
allocated to the tubers leaving none for the foliage. The model assumes an LAIdependent proportion of intercepted photosynthetically active and also total solar radiation of the incident radiation. Newly formed dry matter is allocated over stems, leaves, and tubers. Tuber initiation depends on maturity type, day length, and temperature: shorter photoperiods and higher temperatures reduce the time between crop emergence and tuber initiation.

After tuber initiation, the tuber growth rate is temperature dependent and increases until its rate equals the daily LUE-dependent growth rate. LINTUL-POTATO does not take root biomass into consideration as root mass - being difficult to assess - was not measured in the experiments on which the parameterization was based. The model is written in the simulation language FORTRAN and contains 38 parameters and 21 equations. The temperature, variety, and day-length-dependent parameter values were obtained from crop analysis experiments carried out in 1991 and 1992 in Rwanda at two altitudes (short photoperiod, varying temperature regimes), in Tunisia in winter, spring, and autumn (varying photoperiods and temperature regimes) and the Netherlands (long photoperiod and a temperate season). The parameterized model was then validated against independent experimental datasets with various varieties from the Netherlands, Hawaii, Peru, the Philippines, Tunisia, and Israel (Kooman 1995).

\section{LINTUL-POTATO-DSS}

For studies in which crop production needs to be calculated to compare the influence of environmental conditions such as benchmarking, different years or agrozones, or to explore climatic hazards and climate change, a less mechanistic and less complex but more robust - e.g., less sensitive to minor weather effects - model has been derived from LINTUL-POTATO: LINTUL-POTATO-DSS. In this model, a number of adaptations are incorporated based on numerous trials analyzing growth, mainly from the PhD theses of Haverkort (1985), Kooman (1995), and Van Delden (2001) and further fine-tuned with data from various surveys.

\section{Emergence and Crop Development}

Van Delden et al. (2000) studied the early crop development and calculated a conservative - valid across growing conditions and varieties - temperature-dependent relative leaf extension rate of $0.013 \mathrm{~cm}^{2} \mathrm{~cm}^{-2}\left({ }^{\circ} \mathrm{Cd}\right)^{-1}$ under optimal temperatures until an LAI value of 0.75 is reached and a conservative specific leaf area of $270 \mathrm{~cm}^{2} \mathrm{~g}^{-1}$. Another adaptation or simplification was to replace an extinction coefficient, which depends on increased extinction of light within the canopy at higher LAI values, with a direct conversion of LAI into the proportion of intercepted solar radiation by green foliage (Haverkort et al. 1991). Between LAI values of 0 and 3, the relationship is linear, with no radiation intercepted at $\mathrm{LAI}=0$ and $100 \%$ radiation intercepted at an LAI of 3 and above.

In LINTUL-POTATO-DSS, the base temperature for the various processes is $0{ }^{\circ} \mathrm{C}$, more properly Kelvin degree should be used but in crop growth models, this is not the general habit. The model uses the following input data: daily maximum and minimum temperature $\left({ }^{\circ} \mathrm{C}\right)$, solar radiation $\left(\mathrm{MJ} \mathrm{m}^{-2}\right)$, precipitation $(\mathrm{mm})$, and evapotranspiration 
(mm). The model is run with daily data, and in case only monthly values are available, it uses interpolated values as a substitute. Monthly accumulated rainfall data, however, are converted to daily data by equally distributing rainfall over the number of rainy days, and rainy days are stochastically distributed over the month. In this situation, the monthly number of rainy days needs to be added as input. All other model input data is shown in Table 1. The base temperature for, e.g., sprout growth, is $0{ }^{\circ} \mathrm{C}$, and the sprout growth rate equals $0.7 \mathrm{~mm}\left({ }^{\circ} \mathrm{Cd}\right)^{-1}$. This proves to predict actual emergence dates well where temperatures in spring increase gradually (Van Delden et al. 2000), as is the case in temperate maritime climates. However, in locations with a cold continental winter and heavy frosts, spring temperatures usually increase swiftly, while the soil temperature often lacks behind due to the still frozen undersoil. In such conditions, actual soil temperatures need to be inserted or - if unavailable - the average day-night temperature should be used in LINTUL-POTATO-DSS, but with a reduced "sprout growth rate" as to match the modeled and actual time between planting and emergence.

The model assumes that the length of the crop cycle of the variety planted (crop earliness or lateness) in a certain environment matches the length of the available growing season when temperatures are not too high or too low for potato crop growth. When year-round potatoes can be grown, more planting and harvest dates are inserted. The crop partitions dry matter to tubers and foliage such as to arrive at a HI value of 0.75 at maturity. Inserting an earlier harvest date leads to lower calculated yields. To take a lower HI value into account when the crop is harvested earlier, in LINTULPOTATO-DSS, the HI in the model is linearly correlated to thermal time after tuber initiation: $\mathrm{HI}$ is assumed to have a value of 0 , for a number of days after emergence (Kooman and Haverkort 1994), which is shorter for earlier varieties, higher temperatures, and shorter photoperiods, and reaches 0.75 at crop end. Crop end is the moment when the crop is mature or haulms are killed close to maturity. The modeler inserts the date of haulm killing or assumed date of crop maturity (crop death). This is not necessarily the harvest date, as crops in, e.g., the Netherlands are harvested a few weeks after haulm killing and, in e.g., some parts of Africa, Argentina, and Australia often many weeks or even months after complete crop senescence (Caldiz 2007).

\section{Crop Ecological Parameters}

The time between emergence and 100\% ground cover in LINTUL-POTATO-1.0 was made dependent on temperature until LAI equals 0.75. In LINTUL-POTATO-DSS, the temperature dependence is stretched to the LAI value of 3 representing $100 \%$ ground cover: the value of $650{ }^{\circ} \mathrm{Cd}$ between the day of emergence and the day of canopy closure best matches the actual value in crops not subjected to biotic and abiotic stress, well supplied with minerals and water and planted at a density of four plants $\mathrm{m}^{-2}$ as calculated from the best performing field trials carried out as described by Haverkort (1985) and Kooman (1995).

\section{Water Relations}

To simulate water-limited yield using LINTUL-POTATO, Stol et al. (1991), Franke et al. (2011), and Verhagen et al. (1998) calculated the daily crop 
Table 1 Input parameters required for LINTUL-POTATO-DSS (values shown are examples only)

\begin{tabular}{|c|c|c|}
\hline INPUT DATA description & Value & Explanation and range \\
\hline Month of planting & 4 & Value between 1 and 12 (Jan-Dec) \\
\hline Day of month of planting (1-31) & 1 & Value between 1 and 31 \\
\hline Planting depth $(\mathrm{cm})$ & 17.5 & $\begin{array}{l}\text { In centimeters from tuber to hill top, used to } \\
\text { calculate emergence date }\end{array}$ \\
\hline Sprout growth rate $\left(\mathrm{mm}\left({ }^{\circ} \mathrm{Cd}\right)^{-1}\right)$ & 0.7 & \\
\hline Month of tuber number assessment & 7 & $\begin{array}{l}\text { When destructive sample is taken from } \\
\text { representative crop sample: value between } 1 \text { and } \\
12 \text { (Jan-Dec) }\end{array}$ \\
\hline Day of tuber number assessment & 15 & $\begin{array}{l}\text { When destructive sample is taken from } \\
\text { representative crop sample: value between } 1 \\
\text { and } 31\end{array}$ \\
\hline Number of tubers $/ 10 \mathrm{~kg}$ fresh mass & 150 & \\
\hline Month of haulm killing & 9 & $\begin{array}{l}\text { When foliage is desiccated a few weeks prior to } \\
\text { harvest: value between } 1 \text { and } 12 \text { (Jan-Dec) }\end{array}$ \\
\hline Day of haulm killing & 15 & $\begin{array}{l}\text { When foliage is desiccated a few weeks prior to } \\
\text { harvest: value between } 1 \text { and } 31\end{array}$ \\
\hline Month of crop end & 9 & $\begin{array}{l}\text { Date when crop matures (senesces) naturally, } \\
\text { maturity type dependent: value between } 1 \text { and } 12 \\
\text { (Jan-Dec) }\end{array}$ \\
\hline Day of crop end & 15 & $\begin{array}{l}\text { Date when crop matures (senesces) naturally, } \\
\text { maturity type dependent: value between } 1 \text { and } 31\end{array}$ \\
\hline Day of tuber initiation after emergence & 15 & $\begin{array}{l}\text { 5-20 days after emergence, maturity type } \\
\text { dependent }\end{array}$ \\
\hline Rooting depth $(\mathrm{cm})$ & 50 & Depth of soil layer with roots \\
\hline Texture ( $\%$ clay and silt $)$ & 5 & For water-holding capacity estimation \\
\hline DM concentration of tubers $(\%)$ & 21 & Expected or measured \\
\hline Area under irrigation $(\%)$ & 100 & 0 or 100 for a field, intermediate for a region \\
\hline Harvest index $(\%)$ & 75 & At crop end for all crops \\
\hline Degree-days emergence- $100 \%$ crop cover & 650 & Initial crop development \\
\hline $\begin{array}{l}\text { LUE (global solar radiation) }\left(\mathrm{g} \mathrm{MJ}^{-1}\right. \\
\quad \text { radiation intercepted) }\end{array}$ & 1.25 & Light use efficiency \\
\hline $\begin{array}{l}\text { Min. temperature for photosynthesis } \\
\quad\left(T_{\text {average }}\right)\end{array}$ & 3 & $\mathrm{LUE}=0$ if $T_{\text {average }}<3{ }^{\circ} \mathrm{C}$ \\
\hline Min. temp. optimal photosynthesis $\left(T_{\text {average }}\right)$ & 15 & LUE is at optimal value of $1.25 \mathrm{~g} \mathrm{MJ}^{-1}$ \\
\hline Max. temp. optimal photosynthesis $\left(T_{\text {average }}\right)$ & 20 & LUE is at optimal value of $1.25 \mathrm{~g} \mathrm{MJ}^{-1}$ \\
\hline Max. temp. photosynthesis ( $\left.T_{\text {average }}\right)$ & 28 & $\mathrm{LUE}=0$ if $T_{\text {average }}>28^{\circ} \mathrm{C}$ \\
\hline \multicolumn{3}{|c|}{ Optional for approximation of dry matter concentration } \\
\hline \multicolumn{3}{|l|}{ Dry matter of the tuber at tuber initiation } \\
\hline $\begin{array}{l}\text { Amount of nitrogen applied above or } \\
\text { below average }\end{array}$ & $11 \%$ & \\
\hline \multirow{2}{*}{$\begin{array}{l}\text { Amount of potassium applied above or } \\
\text { below average }\end{array}$} & $+50 \mathrm{~kg}$ & \\
\hline & $-40 \mathrm{~kg}$ & \\
\hline $\begin{array}{l}\text { Amount of water received above or below } \\
\text { average }\end{array}$ & $-100 \mathrm{~mm}$ & \\
\hline Percentage clay & $\%$ & Explanation, see text \\
\hline
\end{tabular}


evaporation from Penman-Monteith grass reference transpiration (ETo) and a crop-specific coefficient (using the daily maximum and minimum temperatures, relative humidity, wind speed, solar radiation as input parameters), crop canopy cover, rainfall, and soil evaporation (calculated according to Ritchie, 1972). Water availability was calculated from soil water-holding capacity and precipitation and a water balance dependent on precipitation, drainage, and evapotranspiration.

Where LINTUL-POTATO calculates potential crop yield unlimited by water or nutrient availability nor reduction by biotic factors, LINTUL-POTATO-DSS calculates attainable yields under water-limiting conditions. Moisture stress reduces LUE, and the photosynthesis rate is proportional to the ratio of actual to potential evapotranspiration. The repercussion of lack of water for crop daily growth is thus calculated, as shown in Eq. 1:

$$
Y a t t=Y p o t \times \frac{W a v}{E T P}
$$

where Yatt=attainable yield increment per day, Ypot=potential yield increment per day, ETP=daily evapotranspiration, and Wav=the daily available water from rain and irrigation, its maximum value is that of ETP. Water availability further depends on rooting depth and water-holding capacity and other soil properties. Silt plus clay content of the soil are input parameters used to estimate soil waterholding characteristics such as field water capacity (FWC) and wilting point (WP) according to Bennie and Hensley (2001). Plant available water (PAW) is the amount of water between FWC and WP in $\mathrm{mm}$ water $\mathrm{m}^{-1}$ soil depth. It is assumed that only $50 \%$ of PAW is freely available for plant uptake. Plant stress develops when more than this amount is depleted from the root zone. The cumulative seasonal rainfall and soil water reserve determine the total amount of water available for crop use. Only $80 \%$ of the rainfall is assumed to infiltrate the soil and is available for crop use.

The water deficit factor (WDF) approach to quantify water stress described above can be an oversimplification of reality. A single stress factor calculated for the entire season cannot work well for rain-fed conditions in subtropical and Mediterranean areas, where rainfall is often very poorly distributed over the season. Yields are often higher in a season with lower, but well-distributed rainfall than in one with high, but poorly distributed rainfall. Therefore, the shortage of plant available water is better calculated - when daily rainfall and ETP data are available-with a "tipping bucket" (Van Keulen 1975) approach. A water balance of the rooted soil volume is then included. The balance accounts for the input "rain and irrigation" and the output "evapotranspiration and drainage." At time of planting, the soil water balance is assumed to be at field capacity. If not, the difference between the actual availability and field capacity has to be accounted for in the irrigation need. Daily inputs of rain are leveled with losses due to evapotranspiration. When rain exceeds the soil water content at field capacity, the surplus drains. On the other hand, irrigation deficit and water stress starts to accumulate when the plant available soil water content is depleted for $50 \%$ by evapotranspiration (Van Keulen 1975). 


\section{Tuber Quality Characteristics}

\section{Tuber Size Distribution}

The number of tubers per unit area — contrary to yield — so far cannot be predicted with any accuracy. The number of tubers can be influenced by management factors (Struik et al. 1990), e.g., it can be increased by increasing the number of seed tubers per unit area, larger seed tuber size, and by ample availability of soil water at tuber initiation. Furthermore, the number of tubers formed per plant depends on the number of eyes per seed tuber, the proportion of sprouting eyes, number of emerging main and lateral stems per sprout, the number of main and lateral stolons, and the proportion of stolon ends yielding tubers (Struik et al. 1990). Final tuber number also depends on the proportion of tubers resorbed. All these factors are a result of interaction between variety, seed tuber physiology, and ambient soil and climatic conditions. To date, these interactions have not been elucidated or quantified. Tuber size prediction at crop end therefore requires an assessment of tuber number. This can be done once tuber number has been established, which is assumed to be at two third of the time between planting and crop end. The number of tubers per $10-\mathrm{kg}$ sample at the time of assessment, coupled to the calculated final yield, can be used to calculate the number of tubers per $10 \mathrm{~kg}$ tuber yield at crop end, according to Eq. 2:

$$
N c e=N t a \times \frac{Y a d}{Y c e}
$$

where $\mathrm{Nce}=$ tuber count per $10 \mathrm{~kg}$ at crop end, $\mathrm{Nta}=$ tuber number per $10 \mathrm{~kg}$ sample at the date of tuber number assessment, Yad=yield of tubers at date of tuber number assessment, and Yce=yield of tubers as calculated by LINTUL-POTATO-DSS at the date of crop end. The tuber count per $10 \mathrm{~kg}$ - often used by the industry - is a measure of the tuber size/width distribution, often also assessed with grids of varying sizes, e.g., $<28,28-35,35-50,50-70$, and $>70 \mathrm{~mm}$. For different length to width ratio (L/W) categories of tuber shapes, a relationship between Nce and size distribution needs to be stablished in order to accurately estimate final tuber size distribution. Round tubers with a $\mathrm{L} / \mathrm{W}$ value of 1 have higher mass proportions in the larger tuber size classes at similar Nce values than long-shaped tubers, e.g., $\mathrm{L} / \mathrm{W}=1.8$.

If so desired, the tuber size, Wtav, may also be expressed as the average tuber weight derived from the $10 \mathrm{~kg}$ tuber count, Nce, as shown in Eq. 3.

$$
W t a v=\frac{10 \mathrm{~kg}}{N c e}
$$

\section{Tuber Dry Matter Concentration}

The tuber dry matter concentration (DMC) expressed as percentage dry matter usually is inferred from the specific gravity (Wilson and Lindsay 1969). Starch is heavier than water, so this is usually measured by weighing $5 \mathrm{~kg}$ of tubers under water. Specific gravity closely correlates with percentage of tuber dry matter as determined by oven 
drying cut potato tuber parts. In the text below, specific gravity data from literature were transformed into dry matter percentage of potatoes (Wilson and Lindsay 1969).

We assume that when tubers are initiated, they have the same DMC as the stolons they are derived from. The DMC of stolons, stems, and leaves closely approaches $11 \%$ (Haverkort, 1985) and at maturity often varies between 16 and 26\%, depending on the variety, environmental conditions, and crop management. LINTUL-POTATO-DSS calculates intermediate $\mathrm{DMC}$ values by interpolating linearly between $11 \%$ at tuber initiation (coinciding with $\mathrm{HI}=0$ ) and the expected $\mathrm{DMC}$ given as input when the crop is harvested at maturity. The expected DMC is inserted by the user of LINTULPOTATO-DSS, based on long-term observations of this parameter for the specific variety. A linear relationship is assumed as both DMC and HI follow a sigmoid pattern. This value can be used to estimate fresh crop yields at harvests earlier than crop end, e.g., at the tuber number per $10 \mathrm{~kg}$ count and at premature seed crop haulm killing. In Eq. 4,

$$
T d m c=a \times H I+11 \%
$$

where $a$ is the slope, i.e., the increment of Tdmc \% with each 0.01 increase of HI.

The HI varies between 0 at tuber initiation to 0.75 at crop end. The value of $a$ depends on the expected Tdmc at crop end and may vary between 6 , leading to a Tdmc of $15.5 \%$, and 20 , resulting in a Tdmc value of $26 \%$. When for example the relation factor $a=15$, Tdmc $=11 \%$ at tuber initiation and at crop end, it is $(15 \times 0.75)+11=$ $11.25+11=22.25 \%$.

Unlike total and tuber dry matter yields that can be simulated and predicted with accuracy, tuber dry matter concentration so far cannot be predicted closer than within a range known for a certain variety-environment-management combination. An approximation of a deviation from the average dry matter combination (average recorded by the grower based on long term experience with average conditions) may be established by taking nitrogen and potassium fertilization, water availability, temperature during the growing season, and soil sandiness into account. For each of these factors, only one example was taken from a large body of literature, which seems only limited to these five factors, to show its effect on tuber dry matter concentration according to Eq. 4.

Increased nitrogen fertilizer doses usually lead to lower dry matter concentrations. From results of experiments in Australia with increasing $\mathrm{N}$ doses ranging between 68 and $230 \mathrm{~kg}$ of $\mathrm{N}$ applied per hectare, the relationship in Eq. 5, based on data of Victoria (2010) could be established:

$$
\text { Tdmc }=25.0-0.0254 \text { NITapp }
$$

where Tdme is the tuber dry matter concentration (\%) and NITapp is the amount of nitrogen $\left(\mathrm{kg} \mathrm{N} \mathrm{ha}^{-1}\right)$ applied to the crop. Similarly, muriate of potassium $(\mathrm{KCl})$ applications cause a decrease of the tuber dry matter concentration. The same source reports an absolute decrease of Tdmc with $\mathrm{K}_{\text {app }}$ applied $\mathrm{kg} \mathrm{ha}^{-1}$, between 62 and $312 \mathrm{~kg} \mathrm{~K}_{2} \mathrm{O} \mathrm{ha}{ }^{-1}$, according to Eq. 6, based on data of Victoria (2010):

$$
T d m c=24.3-0.0340 \mathrm{Kapp}
$$


Growing potatoes in increasingly wet soil conditions also tends to negatively influence the tuber dry matter concentration. Equation 7 is an example of experiments where crops were supplied with amounts of irrigation water, Wapp in mm per season, varying from 250 to $600 \mathrm{~mm}$ in Australia, according to Eq. 7, based on data of Hegney (2001):

$$
T d m c=22.9-0.0117 \mathrm{Wapp}
$$

Two environmental factors are also known to substantially reduce Tdmc: higher average temperatures during the growing season and lighter, i.e., more sandy soils. Haverkort and Harris (1986) showed that the same potato varieties and seed origin grown simultaneously at altitudes ranging from 2350 to $1350 \mathrm{~m}$ in Rwanda with average day temperatures over the growing season, TEMPmean, ranging from 15 to $22{ }^{\circ} \mathrm{C}$, showed a decreasing $\mathrm{Tdmc}$ as shown in Eq. 8 (Haverkort and Harris 1986):

$$
T d m c=28.0-0.450 \mathrm{TEMPmean}
$$

Haverkort, unpublished data, found that lighter soils with a lower proportion of clay (Pclay), expressed as volumetric percentage of all soil particles, are associated with lower dry matter concentrations in a range of 5 to $35 \%$ clay according to Eq. 9 (derived from unpublished data Haverkort):

$$
\text { Tdmc }=18.2+0.0847 \text { Pclay }
$$

Similar to tuber number, the tuber dry matter concentration cannot be approached with certainty by model calculations. Tuber dry matter concentration may be assessed at the moment of tuber number assessment and, when deviating from a long-term average, a higher or lower concentration may be expected. Currently, the best approach may be to assume an average Tdmc from experience for a given variety, environment, and crop management and calculate an expected deviation based on deviating water and fertilizer supply, weather conditions, and soil type according to Eqs. 5, 6, 7, 8, and 9 leading to Eq. 10 as a follow up of Eq. 4.

$$
\begin{aligned}
T d m c=a \times H I+11.0 & +0.0254(\text { NITav }--\mathrm{NITact}) \\
& +0.034(\mathrm{Kav}--\mathrm{Kact}) \\
& +0.0117(\mathrm{Wav}--\mathrm{Wact}) \\
& +0.45(\text { TEMPav }-- \text { TEMPact }) \\
& +0.084(\text { Pclay-av }-- \text { Pclay-act })
\end{aligned}
$$

When all parameter values are within the average range, no deviation from amount of nitrogen, potassium, and water made available to the crop with average temperatures and clay content, $\mathrm{Tdmc}=\mathrm{a} \times \mathrm{HI}+11.0 \%$ (Eq. 4 ) will be the average tuber dry matter value expected for this crop.

Additionally, LINTUL-POTATO-DSS can be used to study the effect of $\mathrm{CO}_{2}$ on light use efficiency as shown by Haverkort et al. (2013) who explored the effect of climate change in different agroecological zones in South Africa. A higher $\mathrm{CO}_{2}$ 
concentration in the air is associated with a higher light use efficiency. Haverkort et al. (2013) established the following equation:

$$
\mathrm{LUE}=1.25+((\mathrm{ACC}-360) \times 0.001875)
$$

where LUE is the light use efficiency $\left(\mathrm{g} \mathrm{MJ}^{-1}\right)$ and ACC is the actual atmospheric $\mathrm{CO}_{2}$ concentration (ppm). The light use efficiency at $550 \mathrm{ppm}$ as expected in 2050 will lead to a $28 \%$ increase of LUE valid in 2000 with an atmospheric $\mathrm{CO}_{2}$ concentration of 360 ppm.

\section{Validation of LINTUL-POTATO-DSS}

Kooman (1995) parameterized LINTUL-POTATO-1.0 with field experiments with various early and late maturing varieties each in the Netherlands' rainy summer, in the Mediterranean autumn, and spring seasons and in equatorial mid-elevations and highlands. To validate the parameterized model, he subsequently compared model performance with independent results, not used to parameterize the model, from variety, planting date, shading, altitude, and seed tuber age trials in the Netherlands, Hawaii, Israel, the Philippines, Peru, and Tunisia reported in literature.

Figure 1 shows the comparison of the observed and simulated data calculated with both versions of LINTUL-POTATO. The LINTUL-POTATO-DSS model output overestimates observed data by $6 \%$ on average, which gave points closer to the $y=x$ line than the original model, which overestimates observed data with $14 \%$ and thus showing an improvement of performance over the LINTUL-POTATO-1.0 version. The mean absolute error (MAE) as well as the root mean squared error (RMSE) between observed and simulated decreased from 0.063 to 0.0596 (MAE) and 43.7 to 41.8 (RMSE) for LINTUL-POTATO-1.0 to LINTUL-POTATO-DSS, respectively, and the modeling efficiency improved from 0.37 to 0.46 , indicating that the simulated values of LINTUL-POTATO-DSS compared to those of LINTUL-POTATO-1.0 describe the correlation in observed data better than the mean of the observations (Loague and

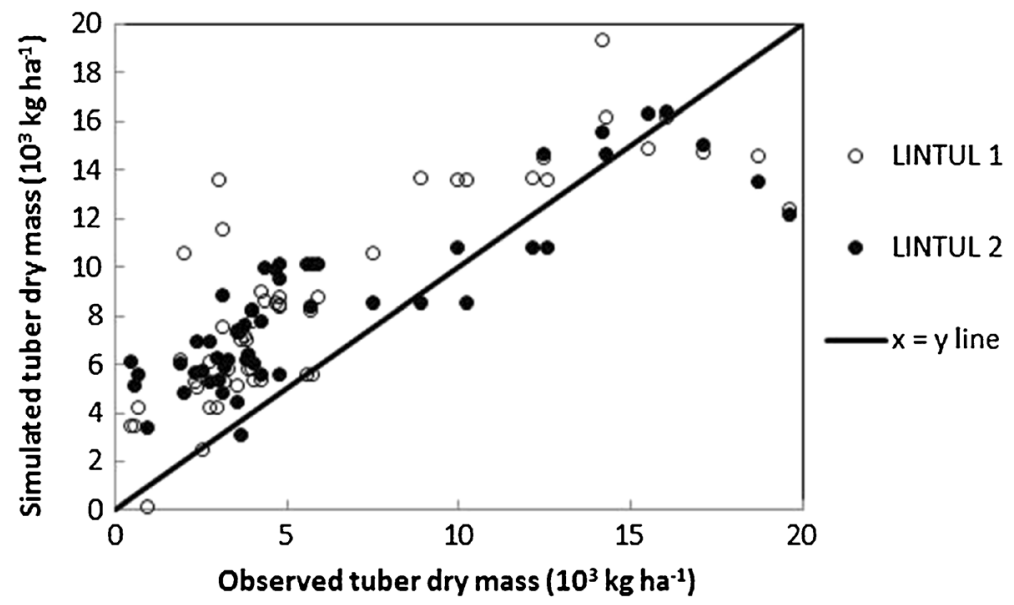

Fig. 1 Simulated versus observed tuber dry matter at final harvest for a series of experiments in different climates. Drawn line: simulated=observed 
Green 1991). Both LINTUL versions simulated much higher values than observed when observed yields were low demonstrating that in general low yields result from inadequate management rather than from suboptimal growing conditions.

\section{Output and Examples of Model Performance}

For studies on benchmarking of production environments, agroecological zoning, climatic hazards and change, and comparison of actual/potential yields (Caldiz et al. 2001; Molahlehi et al. 2013), the need was felt to develop from the original LINTULPOTATO-1.0 model a derivative LINTUL-POTATO-DSS with fewer equations - that would reduce the number and extend of the sources of error in calculations - and fewer parameters, thereby reducing the amount of input data required. LINTUL-POTATO-1.0 has 21 equations and 38 parameters for potential tuber dry matter yield calculations, whereas LINTUL-POTATO-DSS has only three rates: those of emergence, growth, through LUE, and distribution, through HI, and associated equations. Moreover, it is able to calculate water limited production. It uses two equations, one calculates waterholding capacity and another one yield related to relative water availability. Moreover, it estimates tuber quality characteristics such as tuber size and dry matter concentration. The simulation model LINTUL-POTATO-DSS calculates for instance output data as shown in Table 2.

Examples of the use of LINTUL-POTATO-DSS or closely resembling versions are shown by Franke et al. (2011) for yield gap analysis of different growers in the same growing production system in South Africa, by Haverkort et al. (2013) to explore the effect of climate change on potato yield and water use efficiency and by Haverkort et al. (2014) analyzing yield gaps in potato production systems and agroecologies in Chile. The ability of the model to correctly predict actual yields was shown by Machakaire et al. (2015) using the model to forecast yield and tuber size of processing potatoes in different South African environments.

Table 2 Some output data of LINTUL-POTATO-DSS (values shown serve as example only)

\begin{tabular}{|c|c|c|}
\hline Output & Value & Explanation \\
\hline Days between planting and emergence & 28 & Emergence: when $50 \%$ of the plants have emerged \\
\hline Days from emergence to $100 \%$ ground cover & 49 & Initial crop canopy development \\
\hline Days from $100 \%$ ground cover to haulm killing & 90 & Period of $100 \%$ light interception \\
\hline DM tuber yield ( $\left.\mathrm{t} \mathrm{DM} \mathrm{ha}{ }^{-1}\right)$ at haulm killing & 16.8 & \multirow{2}{*}{$\begin{array}{l}\text { Dry tuber yield at any day light interception is } \\
\text { stopped }\end{array}$} \\
\hline DM tuber yield ( $\left.\mathrm{t} \mathrm{DM} \mathrm{ha}{ }^{-1}\right)$ at crop end & 17.5 & \\
\hline Fresh tuber yield $\left(\mathrm{t} \mathrm{ha}^{-1}\right)$ at haulm killing & 78.9 & \multirow{2}{*}{$\begin{array}{l}\text { Fresh tuber yield at any day when light interception } \\
\text { is stopped }\end{array}$} \\
\hline Fresh tuber yield ( $\left.\mathrm{t} \mathrm{ha}^{-1}\right)$ at crop end & 81.5 & \\
\hline $\begin{array}{l}\text { Quality parameter: no. of tubers } / 10 \mathrm{~kg} \\
\text { fresh weight }\end{array}$ & 88 & Background for size distribution \\
\hline Soil field capacity (mm water(m soil $)^{-1}$ ) & 100 & Upper limit of plant available water \\
\hline Accumulated precipitation deficit (mm) & 43 & Cumulative PET minus plant available water \\
\hline Irrigation need (mm) & 18 & $\begin{array}{l}\text { Amount if irrigation water needed in addition to } \\
\text { precipitation to meet crop water demand }\end{array}$ \\
\hline
\end{tabular}


Here follow two additional examples of the use of LINTUL-POTATO-DSS with illustrations: (a) the calculation of the effect of irrigation as of a predefined moment during the growing season when before none was applied and (b) prediction of final tuber size (distribution) some six weeks prior to final harvest.

Figure 2 shows the effect of irrigation - upper lines irrigated - of rain fed crops in the Netherlands, Lelystad area (Fig. 2a), and in South Africa, Bloemhof area at the border between the Free State and North West (Fig. 2b), both on sandy soils with 1\% clay. In both areas, a certain year, 2003 in Lelystad and 2008 at Bloemhof, was chosen when crop yield was simulated with actual weather until mid-season with and without irrigation. Initially, there is no difference between the rainfed and irrigated crop - a single line - as the crops do not yet suffer from drought because of sufficient residual water in the soil profile. As of day 80 in the Netherlands and as of day 40 in South Africa, the nonirrigated crop total dry matter production stays behind. As of day 100 in the Netherlands and as of day 65 in South Africa, the model calculates total dry matter production in the so far either or not irrigated treatments with and without irrigation with the actual weather data of nine adjacent years. It is obvious that irrigated and rainfed yields in the Netherlands are higher than in South Africa. It is also clear that the year to year variation in South Africa is much higher than that in the Netherlands and finally, that the impact of irrigation in South Africa is much higher than that in the Netherlands. Such LINTUL simulation exercises assist growers in making decisions for investment in irrigation equipment and to decide to irrigate or not during the growing season, especially when water supply is budgeted this may be an issue. Moreover, such work is important for yield estimations and the range of yields, e.g., for a McCain to estimate the supply they can expect (average), and what they can expect if weather conditions are going to be unfavourable.

An exercise of prediction of tuber size by LINTUL-POTATO-DSS is shown in Table 3. Ten-year weather data were taken from Lelystad, the Netherlands, and planting dates in LINTUL-POTATO-DSS were set at April 10. Yield was first calculated for August. As we did not have $10 \mathrm{~kg}$ tuber counts for these dates, we-for example, sake - assumed that the number was 150 for 2001 and proportional to yield in the other years. Then, using long-term average rain-fed weather conditions as input in the model calculated the final yield for each year. So, it also calculated the weight increase of the $10 \mathrm{~kg}$ present on August 1; hence, the new $10 \mathrm{~kg}$ tuber count was calculated. As a
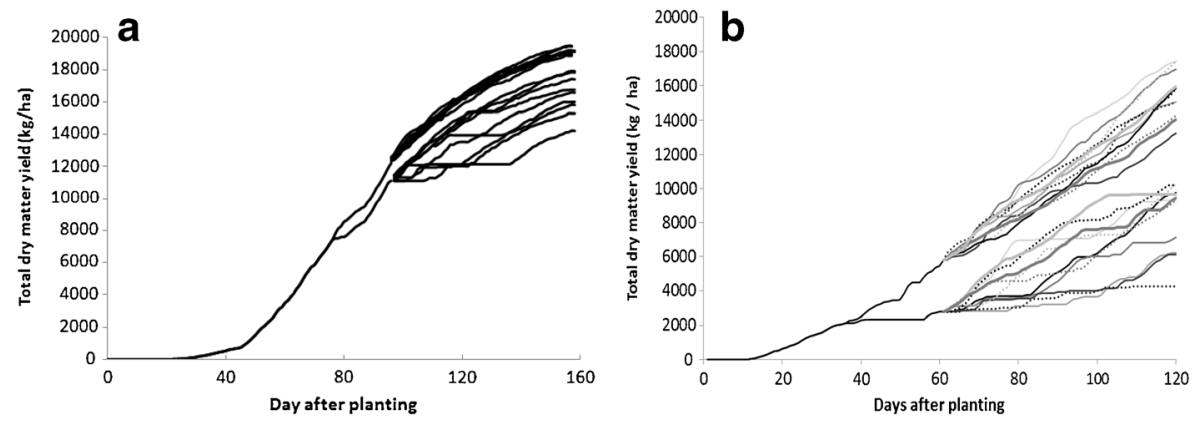

Fig. 2 Simulated total dry matter yield with LINTUL-POTATO-DSS with a single year real-time weather input with and without irrigation until mid-season, irrigation being responsible for the observed bifurcation. After mid-season, dry matter is calculated of both irrigated and nonirrigated treatments until crop end using weather data of nine adjacent years. a Lelystad, 2003; b Bloemhof, 2008 
Table 3 Results of tuber count estimates at the end of the growing season when a presampling is done on August 1

\begin{tabular}{lllll}
\hline & $\begin{array}{l}\text { Simulated yield, } \\
\text { August 1 } \\
\left(\mathrm{t} \mathrm{ha}^{-1}\right)\end{array}$ & $\begin{array}{l}\text { Simulated yield, } \\
\text { September 15 } \\
\left(\mathrm{t} \mathrm{ha}^{-1}\right)\end{array}$ & Number of tubers/10 kg & \\
\hline Year & & & On August 1 (assumed) & $\begin{array}{c}\text { Simulated at crop end } \\
\text { on September 15 }\end{array}$ \\
2001 & 39 & 74 & 150 & 79 \\
2002 & 36 & 71 & 165 & 83 \\
2003 & 35 & 70 & 167 & 84 \\
2004 & 38 & 73 & 154 & 80 \\
2005 & 35 & 70 & 167 & 84 \\
2006 & 24 & 59 & 244 & 99 \\
2007 & 42 & 77 & 139 & 76 \\
2008 & 37 & 72 & 158 & 75 \\
2009 & 41 & 78 & 143 & 91 \\
2010 & 29 & 64 & 201 & 16.75 \\
STDEV & 5.48 & 7.28 & & 75 \\
\hline
\end{tabular}

hypothetical example, the model input is $18 \%$ dry matter on August 1 and $21 \%$ at crop end on September 15. Based on such prediction, growers, traders, or factories may set prices and predict raw material value. In years with high initial tuber counts such as 2006 with 244 tubers per $10 \mathrm{~kg}$ counted on August 1, the yield between sampling date -August 1 - and at crop end more than doubled due to good growing conditions resulting in 99 tubers per $10 \mathrm{~kg}$ at crop end, till the highest in this 10-year series. This information is useful to gain insight into the crop value for an individual grower who may want to kill the crop earlier or later depending on the value of tuber size and for a processing factory in the area where it sources its raw material to pre-assess if total requirements will be met with the area contracted or if more raw material should be looked for in the open market.

\section{Final Remarks}

Over the last 20 years, LINTUL-POTATO underwent drastic changes resulting in fewer equations and parameters but with more empirical data. Due to these changes, the model became more robust and calculates or predicts yields closer to those observed. Moreover, the water relations assist in making the model useful in assessing water use efficiencies and irrigation needs. It has proven to be of use to ex ante assessments of potato areas before investing in potato processing facilities. Such investments greatly depend on variation in crop yields and water need among years and agrozones, and weather extremes such as droughts and heat waves. Also, the effect of climate change on yield, quality, and water use efficiency is easily evaluated, including the beneficial effect of increased ambient $\mathrm{CO}_{2}$ levels on crop growth. The inclusion of relevant crop parameters such as average tuber size and dry matter concentration further make 


\section{LINTUL-POTATO-DSS a useful Decision Support tool for researchers and agrono- mists in the potato sector.}

Open Access This article is distributed under the terms of the Creative Commons Attribution 4.0 International License (http://creativecommons.org/licenses/by/4.0/), which permits unrestricted use, distribution, and reproduction in any medium, provided you give appropriate credit to the original author(s) and the source, provide a link to the Creative Commons license, and indicate if changes were made.

\section{References}

Alberda T (1962) Actual and potential production of agricultural crops. Neth J Agric Sci 10:325-333

Bennie ATP, Hensley M (2001) Maximizing precipitation utilization in dryland agriculture in South Africa-a review. J Hydrol 241:124-139

Caldiz DO (2007) Producción, cosecha y almacenamiento de papa en la Argentina. McCain Argentina SA BASF Argentina SA, Balcarce and Buenos Aires, p 226

Caldiz DO, Gaspari FJ, Haverkort AJ, Struik PC (2001) Agro-ecological zoning and potential yield of single or double cropping of potato in Argentina. Agric Forestry Meterol 109:311-320

De Wit CT (1964) Photosynthesis of leaf canopies. Agricultural Research Report 663, Pudoc, Wageningen, p 57

Franke AC, Steyn JM, Ranger KS, Haverkort AJ (2011) Developing environmental principles, criteria, indicators and norms for potato production through field surveys and modelling. Agric Syst 104:297-306

Haverkort AJ (1985) Relationships between intercepted radiation and yield of potato crops under tropical highland conditions. PhD Thesis University of Reading. 258.

Haverkort AJ, Harris PM (1986) Conversion coefficients between intercepted solar radiation and tuber yields of potatoes under tropical highland conditions. Potato Res 29:529-533

Haverkort AJ, Kooman PL (1997) The use of modeling growth and development in ideotyping of potato under conditions defining, limiting and reducing yields. Euphytica 94:191-200

Haverkort AJ, Uenk D, Veroude H, Van De Waart M (1991) Relationships between ground cover, intercepted solar radiation, leaf area index and infrared reflectance of potato crops. Potato Res 34:113-121

Haverkort AJ, Franke AC, Engelbrecht FA, Steyn JM (2013) Climate change and potato production in contrasting South African agro-ecosystems. 1. Effects on land and water use efficiencies. Potato Res $56: 31-50$

Haverkort AJ, Sandaña P, Kalazich J (2014) Yield gaps and ecological footprints of potato production systems in Chile. Potato Res 57:31

Hegney M (2001) Specific gravity of potatoes. Farmnote/Western Austral. Dep. of Agriculture

Kooman PL (1995) Yielding ability potato crops as influenced by temperature and day-length. Thesis Wageningen University. ISBN 90-5485-362

Kooman PL, Haverkort AJ (1994) Modelling development and growth of the potato crop influenced by temperature and day length: LINTUL-POTATO. In: Haverkort AJ, MacKerron DKL (eds) Ecology and modelling of potato crops under conditions limiting growth. Kluwer Academic Publishers, Dordrecht, pp 41-60

Loague K, Green RE (1991) Statistical and graphical methods for evaluating solute transport models: overview and application. J Contam Hydrol 7:51-73

Machakaire, ATB, Steyn JM, Caldiz DO, Haverkort AJ (2015) Forecasting yield and tuber size of processing potatoes in different South African environments using the LINTUL-Potato model. Potato Research Submitted

Molahlehi L, Steyn JM, Haverkort AJ (2013) Potato crop response to genotype and environment in a subtropical highland agro-ecology. Potato Res 56:237-258

$\mathrm{Ng}$ E, Loomis RS (1984) Simulation of growth and yield the potato crop. Simulation Monographs, Pudoc, Wageningen

Ritchie JT (1972) Model for predicting evaporation for a row crop with incomplete cover. Water Resources Res 5:1204-1213

Ritchie JT, Griffin TS, Johnson BS (1995) SUBSTOR Functional Model of Potato Growth, development and yield. In: Kabat $\mathrm{P}$ et al (eds) Modelling and parameterization of the soil-plant-atmosphere system: a comparison of potato growth models. Wageningen, Wageningen Pers, pp 401-435

Spitters CJT (1990) Crop growth models: their usefulness and limitations. Acta Hortic 267:349-368 
Spitters CJT, Schapendonk AHCM (1990) Evaluation of breeding strategies for drought tolerance in potato by means of crop growth simulation. Plant Soil 123:193-203

Stol W, De Koning GHJ, Haverkort AJ, Kooman PL, Van Keulen H, de Vries FWT P (1991) Agro-ecological characterization for potato production, A simulation study at the request of the International Potato Center (CIP). CABO-DLO, Report 155, Lima, Peru

Struik PC, Haverkort AJ, Vreugdenhil D, Bus CB, Dankert R (1990) Manipulation of tuber size distribution of a potato crop. Potato Res 33:417-432

Van Delden A (2001) Yielding ability and weed suppression of potato and wheat under organic nitrogen management. PhD. Thesis, Wageningen University. ISBN 90-5808-519-8

Van Delden A, Pecio A, Haverkort AJ (2000) Temperature response of early foliar expansion of potato and wheat. Ann Bot 86:355-369

Van Diepen CA, Wolf J, Van Keulen H, Rappoldt C (1989) WOFOST: a simulation model of crop production. Soil Use \& Manag 5:16-24

Van Keulen H (1975) Simulation of water use and herbage growth in arid regions. Simulation Monographs, Pudoc, Wageningen

Van Keulen H, Penning de Vries FWT, Drees EM (1982) A summary model for crop growth. In: Van Laar HH (ed) Simulation of plant growth and crop production. Simulation Monographs, Pudoc, Wageningen, pp 87-97

Verhagen A, Uithol PWJ, Grashoff C, Haverkort AJ (1998) Agro-ecological zoning of potato worldwide potential and water limited yields. Wageningen AB-note 151:25

Victoria (2010) Potatoes: factors affecting dry matter. Note Number: AG0323. State Government of Victoria Department of Environment and Primary Industries

Wilson JH, Lindsay AM (1969) The relationship between specific gravity and dry matter content of potato tubers. Am Potato J 46:323-334 